\title{
ZONAS ARQUEOLÓGICAS Y GESTIÓN DEL TERRITORIO EN LA CIUDAD DE ARICA (CHILE)
}

\author{
ARCHAEOLOGICAL ZONES AND LAND MANAGEMENT IN ARICA CITY (CHILE)
}

\author{
Álvaro Luis Romero Guevara* y Rolando Ajata López**
}

\begin{abstract}
Las ininterrumpidas intervenciones sobre el patrimonio arqueológico en la ciudad de Arica se deben a que esta se instaló en áreas que habían sido ocupadas de manera continua por diversas poblaciones locales. Esta situación ha significado la elaboración de una interesante secuencia histórica que se remonta a los primeros pobladores de cazadores-recolectores. Sin embargo, este conocimiento no ha servido para modificar las ideas generales que poseen los habitantes de la ciudad respecto del patrimonio arqueológico presente bajo sus pies, ni menos establecer procedimientos de planificación territorial en la ciudad.

El artículo presenta un diagnóstico inicial acerca de los antecedentes arqueológicos presentes en el interior de la ciudad de Arica, identificando las áreas o zonas más sensibles de contener determinados tipos de evidencias arqueológicas. Del mismo modo, se discutirá cómo los instrumentos de planificación urbana podrían ayudar a establecer procedimientos de arqueología preventiva con el objeto de proteger y dar uso adecuado a los materiales y conocimientos arqueológicos.
\end{abstract}

Palabras claves: Gestión del Patrimonio Arqueológico, Planificación Territorial, Arqueología de Arica.

Frequent interventions on the archaeological heritage in the city of Arica are because it is installed in areas that were occupied continuously by various pre-Hispanic local populations. This situation has led to the development of an interesting historical sequence that goes back to the first settlers of hunter-gatherers. However, this knowledge has not served to alter the general ideas that have the inhabitants of the city with respect to this archaeological heritage under their feet, let alone establish procedures for territorial planning in the city.

This paper presents an initial analysis on the archaeological background present in the inner city of Arica, identifying the most sensitive zones to contain certain types of archaeological evidence. Similarly, will discuss how urban planning instruments could help establish procedures for preventive archeology in order to protect and use appropriate materials and archaeological knowledge.

Key words: Archaeological Heritage Management, Territorial planning, Archaeology of Arica.

\begin{abstract}
A la memoria de Luis Álvarez Miranda (1926-2004), pionero en visibilizar el componente arqueológico más remoto en nuestra ciudad.

A la memoria de Oscar Espoueys Bonfiglio (19232013) creador del primer esfuerzo por mapear los sitios arqueológicos en el interior de la ciudad de Arica.
\end{abstract}

\section{Introducción}

A fines de la década de 1960 la Junta de Adelanto de Arica ${ }^{1}$ se encontraba en plena faena de modernizar el Departamento de Arica y la ciudad mediante una serie de inversiones y estudios. Una de las tantas infraestructuras fue el proyecto "Urbanización La Lisera", consistente en la construcción de un sector de viviendas de alto rango frente a una popular playa de la ciudad. Pero el sector escogido ya era reconocido por la existencia de amplios y densos yacimientos arqueológicos. Se tenían datos a partir de los trabajos de Junius Bird en la década de 1940 (Bird 1988[1943]) y el catastro del Museo Regional de Arica de 1959 (Álvarez 1996) que identificó ocho yacimientos denominados "Playa Miller", frente a las playas El Laucho, La Lisera y Brava.

Escuetamente Focacci en su publicación acerca del cementerio prehispánico Playa Miller 7 señala que:

El año 1969-1970 con el auspicio de la Universidad del Norte y el apoyo económico de la Junta de Adelanto de Arica, efectuamos el rescate de los cementerios de playa El Laucho, que iba a ser loteada y urbanizada (Focacci 1974:25).

Sin embargo, a partir de las actas de la Junta de Adelanto de Arica (JAA) se conoce que este apoyo no estuvo exento de tensión y desconfianzas hacia el trabajo de los arqueólogos y del valor de las

* Comisión Asesora de Monumentos Nacionales, Región de Arica y Parinacota, Arica, Chile. Correo electrónico: alrogu@yahoo.com ** Colegio de Arqueólogos de Chile, Arica, Chile. Correo electrónico: rolandoajata@ gmail.com 
evidencias arqueológicas. En una sesión de fines de 1969, la Gerencia Técnica de la JAA y su Comisión Turismo, Urbanismo y Obras Públicas estudió la solicitud de los arqueólogos de la Universidad del Norte para prolongar por tres meses más las actividades de rescate, que ya se habían extendido por casi un año y que habían permitido el salvataje de aproximadamente 500 contextos funerarios ${ }^{2}$.

Los miembros de la JAA argumentaron por el cese de las excavaciones, señalando que el yacimiento era tan grande que difícilmente los tres meses solicitados serían suficientes. Además, indican que en el yacimiento "la Universidad no está haciendo ningún estudio arqueológico propiamente, sino que (solo) están rescatando piezas" (JAA a: 4).

También indican la necesidad de conocer el "real" valor de las piezas arqueológicas que se rescataban para saber si "superaría al valor de la urbanización" o al contrario, se trataba de piezas "similares a las ya extraídas". Sucedió que los depósitos y entierros más superficiales, de períodos prehispánicos tardíos (1000 a 1500 d.C.), habían sido los más numerosamente rescatados por las actividades de urgencia. Mientras que, los depósitos más antiguos, relacionados con el componente Chinchorro (Álvarez 1969) y el componente agrícola inicial (Focacci 1974), que se encontraban a una profundidad entre 50 y $100 \mathrm{~cm}$, no habían sido recuperados con igual intensidad.

Explicado este contexto a la JAA, los investigadores lograron un plazo de diez días para recabar más antecedentes en terreno y determinar el potencial de los depósitos más antiguos y profundos. Terminado dicho tiempo, la Gerencia Técnica de la JAA expone que "desde que se otorgó el plazo, de los 12 hombres que se encontraban en faenas, ellos se han reducido a tres personas, por lo que se deduce que la urgencia no está tan fundamentada" (JAA b: 23).

Adicionalmente, la Gerencia Técnica indica que existen otros lugares con restos del componente más antiguo, como

"Pisagua Viejo, en Caleta Vítor, en la explanada sur de Camarones, en la zona del Chinchorro, donde se ubicó el Barrio Industrial, en el sector del Morro, bajo los estanques de agua potable y en otros puntos. En consecuencia, no se trata de un sector único, como el énfasis que los investigadores le dan" (JAA b: 23).

Viendo que los argumentos de desarrollo e interés público estaban ganando por sobre los relativos al interés científico, los arqueólogos señalaron que "si la Junta inicia los trabajos, la Universidad cursaría una denuncia a la Dirección de Bibliotecas, Museos y Archivos [sic], la que ordenaría de inmediato la paralización de los trabajos" (JAA b: 23).

Finalmente, tras la recomendación de la Gerencia Técnica, en enero de 1970, el Directorio de la JAA decide terminar las investigaciones e iniciar los trabajos de urbanización, indicando que:

\section{se puede cooperar con la Universidad para investigar en otras zonas y que el interés demostrado en la agilización de las investigaciones es más bien relativa y que el rescate adicional de piezas, sin mayor estudio, como se está haciendo, agrega poco a lo ya realizado (JAA b:23).}

La forma en que sucedieron los hechos y los argumentos argüidos por ambos grupos (planificadores urbanos y arqueólogos), pese a que ocurrieron hace más de 40 años, son muy similares a los que se enfrentan en la actualidad cuando suceden hallazgos arqueológicos durante diferentes tipos de obras públicas y privadas. Como Estado, como colectivo de arqueólogos y como comunidad local no se ha podido establecer un procedimiento estándar y un lenguaje común, que permita dirimir la frecuente contraposición entre conservación de restos arqueológicos y el desarrollo urbanístico.

Si no se establecen reglas claras de cómo y cuándo se llevan a efecto rescates arqueológicos, el construir en medio de un territorio con restos identificables de una ocupación continua por más de ocho mil años, seguirá viéndose como un problema. Al contrario, si se identifican las áreas de la ciudad con mayor probabilidad de hallazgos y se señalan los deberes de los inversionistas, los profesionales y las entidades del Estado, se podría entender el contexto arqueológico en que está inserta la ciudad de Arica como una oportunidad. Así, el conocimiento otorgado por los estudios arqueológicos y el proceso social derivado de dichas actividades podrían ser entendidos como un plus, tanto para los aspectos netamente científicos, de identidad cultural, e incluso para el desarrollo turístico.

El presente artículo presenta un diagnóstico inicial acerca de los antecedentes arqueológicos presentes en el interior de la ciudad de Arica, identificando las áreas más sensibles de contener determinados tipos de evidencias arqueológicas. Del mismo modo, se discutirá cómo los instrumentos 
de planificación urbana podrían ayudar a establecer procedimientos de arqueología preventiva con el objeto de proteger y dar uso adecuado a los materiales y conocimientos arqueológicos. Tras una comparación entre los procedimientos realizados en otros países de Europa y nuestros actuales instrumentos de planificación, se proponen metodologías factibles de usar en el caso de estudio, así como propuestas normativas que permitan cambios favorables a la protección y gestión.

\section{Arqueología en la ciudad de Arica}

En el siglo XVI los conquistadores españoles cimentaron la ciudad de Arica sobre un territorio intensamente ocupado durante épocas prehispánicas, que además presentaba condiciones naturales para la conservación de sus restos materiales. Por esta razón, desde temprano llamó la atención a viajeros y naturalistas de los siglos XVIII y XIX la importante riqueza arqueológica emplazada en la ciudad (faldeos del Morro) y en sus cercanías (playas de la Costa Sur) $^{3}$.

Sin embargo, uno de los primeros relatos acerca del potencial arqueológico en la ciudad no tiene que ver con los restos prehispánicos, sino sobre las ruinas de la antigua ciudad de Arica establecida hacia el sector de la desembocadura del río San José hasta los sucesos del terremoto y tsunami de 1604, que la trasladaron hasta el actual emplazamiento a los pies del morro:

En 1605 [sic], el 26 de Noviembre, el mar conmovido por un temblor, la inundó súbitamente y destruyó la mayor parte de ella; todavía se ven los vestigios de las calles que se extienden a casi un cuarto de legua del lugar donde está situada (Frezier 1982 [1713]:140).

El arribo de una arqueología sistemática en la primera mitad del siglo XX, por medio de M. Uhle (1919), J. Bird (1988 [1943]), G. Mostny (1944) y R. Schaedel (1957) debe ser entendido como parte del proceso de chilenización impulsado por Santiago, con el objeto de apropiarse de los materiales y conocimientos del pasado remoto de un territorio en disputa (Gänger 2009). Pero también sirvió para motivar el establecimiento de un equipo local y autodidacta de investigadores, compuesto por P. Dauelsberg, G. Focacci, L. Álvarez y S. Chacón, quienes formaron en 1958 el Museo Regional de
Arica (Lara 1972-1973) con su correspondiente Boletín (Álvarez 1996) ${ }^{4}$.

Como parte de políticas centrales para potenciar el desarrollo de esta zona limítrofe, en 1953 se crea el Puerto Libre y en 1958 la Junta de Adelanto de Arica, comentada anteriormente. Estas políticas impulsaron la industrialización, el comercio y el turismo de la ciudad, incrementando el crecimiento urbano, mediante la migración tanto desde el centro de Chile, como desde los pueblos interiores. Entonces, el equipo de investigadores del Museo Regional de Arica logró conjugar la experiencia científica de la arqueología "extranjera" de la primera mitad del siglo XX con la urgencia por rescatar los yacimientos que estaban siendo afectados directamente por el crecimiento de la ciudad, el incremento del área cultivable en los valles y el saqueo que se venía practicando desde siglos atrás. De esta forma, el inicio de la investigación arqueológica local tuvo una doble función: para reconstruir el pasado remoto de la Región, por un lado, y para hacerse cargo de la gestión del patrimonio arqueológico, por otro.

Entre las décadas de 1960 y 1970 este grupo realiza importantes campañas de rescate arqueológico en la ciudad y en los valles. Aparte de los rescates ya comentados en la costa sur (Playa Miller) se hacen otros en las laderas del Morro de Arica que colindan con la ciudad. Se debe recordar que el trazado de la Calle Héroes del Morro y Calle Morro también fueron ampliaciones urbanas relacionadas con el crecimiento industrial de la ciudad de fines de 1950. Se excavan yacimientos funerarios del período inicial de agricultores (Fase Faldas del Morro) y hacia el poniente se rescatan sitios de pescadores Chinchorro (Dauelsberg 1985; Focacci y Chacón 1989). De estas labores iniciales de arqueología en el interior de la ciudad se va configurando el imaginario colectivo de que el centro de Arica contiene un gran cúmulo de evidencias arqueológicas de alto valor científico, y al mismo tiempo que su rescate implica diferentes tipos de costos para los habitantes de la ciudad.

Desde ese punto, el tránsito hacia una arqueología profesional y universitaria fue rápido, creándose diversas líneas de investigación en tierras altas y tierras bajas, enfocadas en la interpretación de los procesos culturales, en especial de los períodos prehispánicos. En la década de 1980 profesionales de la Universidad de Tarapacá continúan con investigaciones en la costa sur de Arica (Muñoz y Chacama 1982) y en los faldeos del Morro (Allison et al. 1984; Standen 2003). Se vuelve a la terraza 
Chinchorro o Zona Industrial, mediante avisos de hallazgos y sus correspondientes salvatajes (Arriaza et al. 2001; Muñoz et al. 1993). Lo más destacable de este período fue el descubrimiento de un nuevo sector que concentra las evidencias prehispánicas más antiguas de la ciudad (Muñoz et al. 1993). Este hallazgo se localiza en la intersección de la quebrada de Acha y río San José, actual límite urbano del lado sur de Arica.

La arqueología institucionalizada sigue centrada en reconstruir la historia cultural del pasado prehispánico, aunque también hace esfuerzos para poner en valor el patrimonio arqueológico de territorios rurales como recursos turísticos. Tal es el caso de los geoglifos de los valles (Briones y Casanova 2011; Dauelsberg et al. 1975), la arquitectura monumental de precordillera (Chacama et al. 1989-1990; Dauelsberg 1989-1990) e incluso un circuito turístico arqueológico del valle de Azapa (Santoro y Espinosa 2000). Sin embargo, para el caso específico de la ciudad de Arica, el conjunto de datos arqueológicos no ha servido para fines de gestión, como la identificación de potenciales zonas arqueológicas y protección a través de procedimientos e instrumentos de regulación urbana ${ }^{5}$.

Con el inicio del nuevo milenio se crea la legislación ambiental en Chile y se consolida a nivel nacional y regional el Consejo de Monumentos Nacionales $(\mathrm{CMN})^{6}$, haciéndose más frecuente la aplicación de criterios de arqueología preventiva para determinadas obras de urbanización o, al menos, gestionar los correspondientes rescates y salvatajes. Si bien en un inicio estas labores fueron ejecutadas por los mismos arqueólogos de la Universidad de Tarapacá, que realizaban investigaciones académicas, actualmente estas acciones las realizan profesionales independientes, dentro del ámbito de lo que se ha llamado arqueología de impacto ambiental o arqueología por contrato (Carrasco 2006). Además, con una oficina regional del CMN es posible ampliar el rango de control y registro de los hallazgos arqueológicos relacionados con obras e intervenciones de menor escala, que se suceden incesantemente como parte de la dinámica de crecimiento y modificación de la ciudad de Arica.

Pese a que estas labores se hacen más frecuentes en la ciudad de Arica y, en consecuencia, visibles para la comunidad y los planificadores, se mantiene la falta de un procedimiento claro y establecido de manera previa para quienes deseen intervenir en el interior de la ciudad de Arica. Los procedimientos de arqueología preventiva, como las delimitaciones de zonas de resguardo arqueológico y de normas para efectuar diagnósticos arqueológicos, son esenciales para definir anticipadamente las inversiones en tiempo y recursos que permitan efectuar los correspondientes rescates arqueológicos. Sin embargo, el problema no solo deriva en la falta de adecuación de la legislación que regula las construcciones urbanas, sino acerca de qué definimos como Patrimonio Arqueológico y como se establece desde aquella definición lo que se rescata. Esto es crucial para hallazgos en el interior de las ciudades, que es donde se concentra la mayor cantidad de intereses, discursos y visiones acerca del uso del territorio y sus componentes patrimoniales.

\section{La protección del patrimonio cultural y arqueológico}

El Patrimonio Cultural en la legislación chilena está deficientemente conceptualizado, lo que provoca un tratamiento irregular, descoordinado y parcializado a partir de diferentes cuerpos legales y que radica en diferentes instituciones. Las principales legislaciones nacionales que consideran determinado tipo de resguardo para el Patrimonio Cultural son la Ley № 19.300 de Bases Generales del Medio Ambiente, la Ley $\mathrm{N}^{\circ} 19.253$ Indígena y por supuesto, la Ley $\mathrm{N}^{\mathrm{o}} 17.288$ de Monumentos Nacionales. Además, a la fecha hay tres Convenciones Internacionales de la UNESCO relativas al Patrimonio Cultural que han sido ratificadas por el Estado de Chile: sobre la protección del Patrimonio Mundial (de 1972, ratificada en 1980); de Bienes Culturales en caso de conflicto armado (de 1956, ratificada en 2008); y de Salvaguardia del Patrimonio Cultural Inmaterial (de 2003, ratificada en 2008).

Debido a que la Ley de Bases Generales del Medio Ambiente indica implícitamente que el Patrimonio Cultural forma parte del Medio Ambiente, en la práctica constituye el cuerpo legal que otorga la máxima protección de determinados componentes del Patrimonio Cultural (González 2004). Sin embargo, esta protección solo se da en el componente cultural y específicamente arqueológico, que están asociados a un proyecto de inversión (público o privado) que requiera ser sometido a Evaluación Ambiental. Por tanto, la falta de una integración conceptual que permita incluir los diferentes componentes del Patrimonio Cultural, pasados y actuales, 
materiales e inmateriales, redunda en una falta de coordinación entre las instituciones pertinentes del Estado, dificultando, en definitiva, su identificación, protección y gestión ${ }^{7}$.

Pese a que el Patrimonio Arqueológico podría considerarse mejor definido en la Ley $\mathrm{N}^{\mathrm{o}} 17.288^{8}$ referida al Patrimonio Cultural de carácter monumental, esto tampoco asegura su adecuada protección y gestión. A nuestro entender, el carácter universal de esta protección, es decir, a todo evento y sin necesidad de especificar aspectos básicos, como dimensión, delimitación, componentes y valores patrimoniales (aparte del valor científico), limita bastante su resguardo efectivo (ver O'Keefe y Prott 1984, en Temiño 2010). Lo que, junto con el carácter eminentemente reactivo de la legislación citada, que no considera gestiones preventivas o la aplicación de incentivos a los propietarios o vecinos, hace que la conservación del Patrimonio Arqueológico se limite, en el mejor de los casos, a las evidencias arqueológicas de caracteres monumentales, de valores incuestionables y que pueden ser reconocidas ampliamente por la comunidad.

Además, es necesario indicar que para el caso de Arica existe una protección adicional para los yacimientos arqueológicos, dado por el Decreto Supremo No 4867 del 13 de julio de 1967, que declara como Monumentos Históricos ${ }^{9}$ los yacimientos arqueológicos y paleontológicos del Departamento de Arica. Dicha división administrativa funcionó hasta 1974 y coincide en gran medida con la actual Región de Arica y Parinacota.

Volviendo al caso que da inicio al artículo, se debe indicar que la fuente legal para que los arqueólogos amenazaran a la Junta de Adelanto de Arica en 1969 era dicho Decreto Supremo No 4867, ya que la Ley de Monumentos recién es promulgada en 1970. Incluso es posible asumir que la promulgación de este decreto específico para este territorio y en dicha época se basó tanto en la riqueza arqueológica demostrada por las investigaciones previas, como también en las amenazas y riesgos de destrucción debido al desarrollo industrial al cual esta división administrativa se enfrentaba por entonces.

Por otro lado, el antecedente directo de la Ley $\mathrm{N}^{\mathrm{o}} 17.288$, con su protección universal de las evidencias arqueológicas, parece estar en el Decreto Supremo de 1967, único en su género, y que da pie a la actual visión excesivamente experta con que se maneja el Patrimonio Arqueológico, y que como dijimos antes, no asegura su protección efectiva. El axioma aparentemente adecuado de que todas las evidencias arqueológicas, no importando su envergadura y complejidad, son iguales de relevantes y merecen su máxima protección, hace agua tras 40 años de aplicación irregular de una ley reactiva.

Se debe recordar que esta ley se creó en una época en que los arqueólogos se enfrentaban a los planificadores públicos e inversionistas privados, como el caso ya revisado, como únicos garantes en la construcción del pasado remoto de un territorio. Sin embargo, hoy en día sabemos que la Gestión del Patrimonio Arqueológico requiere de un diálogo abierto entre diferentes actores de una sociedad y usuarios del conocimiento experto del pasado (Barreiro 2012). Un diálogo en donde la disciplina esté dispuesta a responder preguntas como "¿Qué se debe conservar?, ¿Dónde se debe investigar?, ¿Qué tiene más valor?, ¿Qué se debe valorizar?" (Fernández 2008:39) ${ }^{10}$.

\section{La planificación territorial en Chile y el patrimonio arqueológico}

El Ordenamiento Territorial nació como un tema de arquitectos y planificadores que se enfrentaron con los efectos negativos que tuvo la industrialización en el ordenamiento tradicional de las ciudades europeas del siglo XIX (Ortúzar 2010). Sin embargo, con las crisis ambientales de posguerra del siglo XX y el surgimiento de la Nueva Geografía, la planificación territorial se convierte en una disciplina científica que abarca todos los ámbitos de la relación entre sociedad en desarrollo y su medio ambiente.

Hoy en día se entiende a la Planificación Territorial como una disciplina que busca entender las aptitudes naturales, económicas y sociales de un territorio, para que estas se puedan desarrollar mediante un conjunto de normas y procedimientos. Con esta política de Estado se busca minimizar los conflictos y contradicciones en el uso del territorio. En esta proyección participa el Estado, tanto como organismo político que dirige el bien común, como un ente administrativo que genera los instrumentos de planificación y ejerce su cumplimiento (Sánchez 2001). En este sentido, esta política de Estado requiere de permanentes revisiones y actualizaciones; incluso, hoy en día se le exige al Estado planificar el territorio mediante una metodología participativa que asegure su sustentabilidad. 
Existen instrumentos de planificación de diferentes escalas, relacionadas con ámbitos regionales y locales. Además, los instrumentos que resultan presentan una aplicabilidad de carácter normativo o indicativo. En el primer caso, corresponden a instrumentos que presentan la fuerza legal para imponer una serie de criterios previamente definidos (Sánchez 2001). Mientras que en el segundo caso, conciernen a instrumentos que solo entregan pautas y recomendaciones para quienes intervengan el territorio con el fin de evitar futuras contradicciones, conflictos o incluso problemas legales.

Para el caso de Chile, sin embargo, la Planificación Territorial no presenta una ley marco que entregue bases explícitas y específicas para el ordenamiento territorial. Más bien, existen una serie de instrumentos normativos e indicativos cuyo objetivo es ordenar determinados espacios o componentes de ellos, pero que se presentan dispersos en diferentes organismos del Estado ${ }^{11}$. Aunque recientemente los Gobiernos Regionales están elaborando Planes Regionales de Ordenamiento Territorial (PROT), estos consisten en instrumentos indicativos que se basan en el análisis de cuatro componentes o sistemas: Costero, Rural, Urbano y Cuenca Hidrográfica (SUBDERE 2011).

Pero en la práctica sigue siendo el Ministerio de Vivienda y Urbanismo (MINVU) con su Ley General de Urbanismo y Construcción (LGUC), la entidad que presenta la mayor incidencia en la planificación normativa del territorio, aunque se limita casi exclusivamente al ámbito urbano (Sánchez 2001). De esta forma, el instrumento nacional de mayor escala geográfica, denominado Plan Regional de Desarrollo Urbano (PRDU), es un instrumento que solo tiene un carácter indicativo y que ofrece recomendaciones en lo relativo al desarrollo de los centros urbanos.

Respecto del componente arqueológico, en 1990 ICOMOS presenta la "Carta de Lausana para la Gestión del Patrimonio Arqueológico" donde se recomienda la aplicación de políticas integradas para la protección del patrimonio arqueológico de manera coordinada con el desarrollo y planificación del territorio. En este sentido, diferentes experiencias extranjeras lo han incorporado como parte integral del medio físico que se requiere identificar y proteger mediante los instrumentos de planificación territorial (Fernández 2008; Llavori de Micheo 1998). Esta identificación en las etapas previas de la planificación se basa en el alto riesgo de destrucción de las evidencias por intervenciones en curso, debido a su escasa visibilidad, pero sobre todo al desigual valor que les dan las personas no especialistas a estos recursos (Munita et al. 2013).

Como se indicó en el apartado anterior, un problema para la gestión efectiva del Patrimonio Arqueológico en Chile es la falta de un diálogo entre los diferentes usos y valores que se les otorgan a los bienes que el Estado ha decidido proteger. Existe incluso una dicotomía entre los bienes arqueológicos entendidos como recursos científicos (prácticamente todos) y los bienes arqueológicos que otros actores sociales reconocen como recursos económicos o socioculturales (Munita et al. 2013). Es por eso que el Patrimonio Arqueológico, pese a estar considerado en los componentes que deben ser incluidos en los PROT y en los PRDU, no cuenta con una metodología específica para su identificación, ni indicaciones de su forma de resguardo (Munita et al. 2013).

Ahora bien, si nos enfocamos en el ámbito netamente urbano, los instrumentos normativos son los Planes Reguladores Comunales (PRC). Estos son elaborados a partir de la LGUC, y directrices del MINVU, mientras que, generalmente, su aplicación está a cargo de la Dirección de Obras Municipales (DOM) de los respectivos municipios. Mediante los PRC se "definen" dos componentes relativos al patrimonio cultural de carácter urbanístico: los Inmuebles de Conservación Histórica y las Zonas de Conservación Histórica (MINVU 2010). Los primeros corresponden a un conjunto de edificaciones que presentan una serie de valores históricos, arquitectónicos, urbanísticos y sociales. Mientras que los segundos corresponden a sectores que presentan valores culturales o urbanísticos o que se relacionen o formen parte del entorno de uno o varios Monumentos Históricos ${ }^{12}$.

Se debe observar que la metodología propuesta para identificar y definir estos componentes del patrimonio cultural urbanístico (MINVU 2010), es de carácter técnico, cualitativo y pese a hablar de "valores sociales" no considera aspectos de participación ciudadana en su valoración. Estos aspectos no se condicen con las actuales metodologías y definiciones del Patrimonio Cultural como un proceso cultural, más que un conjunto dado de objetos (Querol 2010).

Además, los PRC deben "reconocer" los Monumentos Nacionales definidos por el CMN presentes en el interior del Límite Urbano. En 
este sentido, las respectivas Direcciones de Obras podrán permitir intervenciones en los Monumentos Nacionales de la ciudad, siempre y cuando estas cuenten con las autorizaciones previas del CMN. $\mathrm{Al}$ respecto existe información contradictoria emanada desde la misma documentación oficial, que indica que los Monumentos Nacionales que deben ser reconocidos por el PRC corresponden a los Monumentos Históricos y Zonas Típicas (MINVU 2010, Punto 2.b) y también que las cinco categorías de Monumentos Nacionales deben ser reconocidas en la Memoria Explicativa del PRC, en el Plano y en la Ordenanza Local (MINVU, Punto 3).

El PRC de Arica, vigente desde el año 2009, presenta en su Artículo 44 un listado de 24 sitios y áreas arqueológicas que se ubicarían en el interior del Límite Urbano. Se recalca además, que dichos sitios y áreas cuentan con una doble protección por parte de la Ley $\mathrm{N}^{\circ} 17.288$, siendo Monumentos Arqueológicos por el solo ministerio de la ley y Monumentos Históricos de acuerdo con el Decreto Supremo No 4867 de 1967. Sin embargo, debido a que los yacimientos del listado carecen de ubicación y tamaño, ni se presentan en los planos de la ordenanza, se hace bastante difícil su identificación y gestión por parte de la DOM de Arica.

En determinados países, principalmente europeos, el concepto de Arqueología Preventiva se asume desde la elaboración de los instrumentos de planificación del territorio (Querol 2010). El instrumento más sofisticado para diagnosticar y minimizar el daño que pudiera afectar el Patrimonio Arqueológico son los estudios arqueológicos denominados Cartas Arqueológicas o Cartas de Riesgo Arqueológico, aplicadas a regiones o localidades (Fernández 2008; Guillen 2006). Este tipo de estudio corresponde a una completa monografía que incluye un catastro de estudios y hallazgos arqueológicos y el estudio de las actuales edificaciones (para conocer las intervenciones en el subsuelo que han llevado a cabo tales construcciones). De la relación espacial de los hallazgos y sitios registrados, del grado de intervención del subsuelo y mapeo del uso del suelo, se pueden definir Zonas de Resguardo o de Prevención Arqueológica, correspondientes a áreas o lugares donde existen sospechas fundadas de la existencia de evidencias arqueológicas (Querol 2010).

Sin embargo, debido a que el registro inicial de evidencias arqueológicas se basa en hallazgos monumentales y/o indiscutibles, existe siempre un sesgo hacia los tipos de registros ya conocidos. Por tanto, tal como en Arica pudieran ser los cementerios (restos bioantropológicos y momias) los registros más frecuentes, en Europa son esencialmente los restos monumentales de edificaciones asociadas al contexto urbano y su crecimiento. En este sentido, las áreas de resguardo casi siempre coinciden con los centros históricos. Ahora bien, son menos frecuentes las experiencias internacionales para el caso de evidencias arqueológicas preexistentes a la ciudad, como sucede en Arica y en ciertos lugares de los Andes (Lémuz y Aranda 2008).

\section{Actuaciones y entidades arqueológicas}

A continuación exponemos los datos referidos a la ciudad de Arica y la metodología que hemos aplicado para su análisis. Nuestra área de estudio se inscribe dentro de los límites urbanos de la ciudad de Arica definidos en el Plan Regulador Comunal vigente desde 2009. Pero le agregamos un área buffer de $1,5 \mathrm{~km}$ puesto que los límites urbanos pueden ser modificados de acuerdo con las necesidades de ampliación urbana para regular determinados sectores o promover determinados polos de desarrollo ${ }^{13}$.

La recopilación de antecedentes arqueológicos dentro de esta área permitió detectar diferentes tipos de 'descubrimientos' en contextos urbanos, realizados en distintas décadas y situaciones. De manera sintética podemos señalar cuatro tipos de actuaciones arqueológicas relacionadas con estos descubrimientos, de acuerdo con su grado de planificación arqueológica:

a) Registros Fortuitos. Reportes y avisos provenientes de intervenciones donde se registran diferentes evidencias y contextos arqueológicos, involucrando obras públicas o privadas. En algunos de estos casos podrá haber participación de arqueólogos, quienes se limitarán a la recolección de elementos, registro fotográfico y georreferenciación, lo que resultará en información arqueológica de resolución básica.

b) Rescates. Registros generados a partir de hallazgos fortuitos que involucran posteriormente excavaciones arqueológicas. En estos casos, según el tipo de contexto arqueológico identificado, podrán haber intervenciones puntuales o más extensivas, pero siempre con el objetivo de rescatar las evidencias para dar paso a la ejecución de proyectos de intervención urbana. Entre estos casos se encuentran, por ejemplo, la 
construcción del Edificio Johnson (Calle 21 de Mayo esquina Patricio Lynch), intervenciones en Terminal Asocapec (sector sur de la ciudad) y hallazgos de osamentas en terrenos de la ex-Penitenciaria de Arica, calle Baquedano.

c) Reconocimientos Superficiales. Corresponden a inspecciones sistemáticas de tipo pedestre en áreas donde se puede observar sin obstrucciones la superficie del terreno con el objeto de registrar y caracterizar evidencias arqueológicas. Se trata de actuaciones preventivas, donde se obtienen registros fotográficos, georreferenciación y la eventual delimitación de áreas con evidencias arqueológicas. Entre este tipo de casos se encuentra la prospección de los Faldeos del Morro, del borde costero de Arica (Ajata 2011) y del cerro San Miguel (Ajata 2006).

d) Diagnósticos Subsuperficiales. Acciones preventivas que corresponden a intervenciones planificadas del subsuelo, con el objeto de evaluar la presencia de evidencias arqueológicas en áreas arqueológicas potenciales y/o de escasa visibilidad desde la superficie. Se trata de actuaciones preventivas mediante la ejecución de un sistema de pozos de sondeo. Es el caso de la construcción del edificio de Almacenes París (Jofré y Ajata 2009); la remediación de Maestranza Chinchorro (Portilla 2013); la habilitación del Museo de Sitio 'Colón 10'; y los diagnósticos realizados en los Monumentos Históricos de la Antigua Aduana y Catedral San Marcos (Portilla y Ajata 2010a, 2010b).

Toda esta sucesión de actuaciones arqueológicas ha dado origen a una extensa, aunque desigual, base de datos de evidencias arqueológicas. Los registros específicos pueden ser categorizados según el número de evidencias, su variabilidad y sobre todo por su capacidad para entregar información inicial de tipo cronológico y funcional. En este sentido, el uso recurrente de los términos "Sitio Arqueológico" y "Hallazgo Arqueológico" por las instituciones del Estado (CNCA/CMN/SNIT 2010), empleado en su origen para distinguir tipos de evidencias en contextos de cazadores y recolectores de la Patagonia (Borrero y Lanata 1992), no son útiles a nivel práctico para interpretar otros tipos de contextos culturales y territoriales. Por ello, proponemos diferentes categorías de entidades arqueológicas, que tienen como objetivo obtener una gradiente de menor a mayor complejidad dentro de un continuum de contextos arqueológicos posibles de registrar: a) Entidad simple: Correspondiente a uno o pocos elementos arqueológicos distribuidos en un área discreta ${ }^{14}$. Si bien no debería haber una delimitación estricta, podría considerarse a aquellos conjuntos de hasta cinco elementos arqueológicos en un área no mayor a $5 \mathrm{~m}^{2}$. Estas entidades pueden ser o no diagnósticas en términos cronológicos, pero servirán al menos para discernir si se trata de elementos arqueológicos (no en uso, ni de época actual), al mismo tiempo que podrían estar indicando alguna situación arqueológica de mayor complejidad. En este caso, por ejemplo, podrían estar los hallazgos de algunas osamentas humanas, piezas de cerámica o fragmentos textiles sin otros elementos asociados.

b) Entidad compleja: Se refiere al registro compuesto por una entidad discreta pero compleja, como por ejemplo una estructura funeraria, fardo funerario, cuerpo; o bien, un rasgo como un depósito, un muro, entre otros casos. Podría tratarse o no de evidencias arqueológicas diagnósticas en términos culturales, presentes en un área no mayor de $5 \mathrm{~m}^{2}$.

c) Conjunto arqueológico: Se refiere a una distribución mayor de evidencias arqueológicas que las entidades simples, dadas por la superficie que abarca, el número de elementos o la diversidad de ellos, incluyendo incluso diferentes materialidades. Pueden ser conjuntos con elementos arqueológicamente diagnósticos o no. Sin embargo, se trata de conjuntos que no pueden ser caracterizados en forma apropiada o relacionados con alguna función cultural específica. En general se trata de áreas arqueológicas registradas a partir de evidencias superficiales o cortes estratigráficos expuestos que requerirían de excavaciones y sondeos para caracterizarlos de forma adecuada.

d) conjunto arqueológico disturbado: Alude a áreas arqueológicas disturbadas in situ o ex situ, que pueden ser observadas tanto en superficie o estratigráficamente. Estas áreas tienen su origen en la remoción de tierras propia de la actividad urbana contemporánea y no incluirían las intervenciones como parte del contexto arqueológico, es decir, reocupaciones o incluso profanaciones de cementerios ocurridas en tiempos prehispánicos.

e) Yacimiento arqueológico: Se trata de entidades arqueológicas complejas, que generalmente 
poseen una extensión mayor a las entidades simples y presentan una amplia variedad de materialidades arqueológicas. Se caracterizan porque a partir de sus componentes pueden ser adscritas a una cronología determinada y una función cultural consistente con las interpretaciones histórico-culturales de la región. Algunos ejemplos de estos yacimientos son los conchales, cementerios, áreas domésticas $\mathrm{y}$ asentamientos.

f) zona arqueológica: Se trata de un territorio extenso que incluye varios yacimientos y otras evidencias arqueológicas cercanas o superpuestas, de igual temporalidad o de varias temporalidades. Estas zonas podrían asimilarse a las Zonas de Resguardo Arqueológico, presentes en ciertos instrumentos de planificación europeos. Estas zonas deberían ser delimitadas mediante el análisis geográfico del conjunto de evidencias arqueológicas disponibles.

\section{La representación de las entidades arqueológicas}

Como parte del presente análisis, las evidencias arqueológicas fueron representadas en un sistema de información geográfica (SIG) a partir de las diferentes fuentes de datos y resoluciones disponibles. Para el caso de los conjuntos y yacimientos mejor estudiados se disponía de planimetrías con instrumental de topografía o GPS, los que fueron incorporados al SIG mediante georreferencia o lectura de las coordenadas UTM. Para el caso de descubrimientos y actuaciones arqueológicas que no presentaban información geoespacial, estos fueron posicionados en el plano de manera aproximada, de acuerdo con los límites de las propiedades urbanas u otras referencias en las imágenes satelitales disponibles, mediante los servicios de imágenes de ArcGIS y Google Earth. Las entidades arqueológicas georreferenciadas, junto con otras evidencias con coordenadas puntuales, fueron convertidas en polígonos mediante un área buffer. Para el caso de las entidades simples o complejas, cuyas dimensiones exactas no eran conocidas, se les asignó un radio estándar de $0,5 \mathrm{~m}$.

En esta etapa de trabajo fue posible diferenciar, de acuerdo con su extensión, dos grandes grupos: Por un lado, las entidades discretas (simples o complejas); y por otro, los conjuntos y yacimientos arqueológicos. En total se conformó una base de datos conteniendo 485 entidades, de las cuales el $78,1 \%$ corresponde al primer grupo de entidades discretas y el $21,9 \%$ al segundo tipo. Como una forma de agrupar las entidades e identificar "Zonas Arqueológicas" se crearon áreas de influencia alrededor de las mismas. Se asignaron valores arbitrarios de $50 \mathrm{~m}$ de radio para los conjuntos/ yacimientos y $25 \mathrm{~m}$ para las entidades discretas. Las mayores concentraciones, a su vez, fueron agrupadas mediante un área envolvente convexa. De esta manera, se identificaron 43 agrupaciones de evidencias arqueológicas, de las cuales cuatro corresponden a Zonas Arqueológicas (Figura 1). Estas últimas son las siguientes:

1. Zona Arqueológica "Chinchorro" (Figura 2). Corresponde a un área de 71 ha que agrupa a 37 entidades arqueológicas localizadas en torno a la Maestranza Chinchorro entre las avenidas España y Argentina.

2. Zona Arqueológica "Centro" (Figura 3). Corresponde a un área de 43 ha que agrupa a 267 entidades arqueológicas localizadas entre los faldeos del Morro de Arica y las calles Comandante San Martín, 18 de Septiembre y Manuel Blanco Encalada.

3. Zona Arqueológica "El Laucho-La Lisera" (Figura 4). Corresponde a un área de 34 ha que agrupa a 102 entidades arqueológicas localizadas en torno a la urbanización La Lisera, entre Playa El Laucho y Playa Brava.

4. Zona Arqueológica "Nueva Esperanza" (Figura 5). Corresponde a un área de 193 ha que agrupa a 22 entidades arqueológicas localizadas en las inmediaciones de la intersección de los ríos San José de Azapa y Acha. Comprende el Terminal Agropecuario, población Nueva Esperanza, cerro San Miguel y sector campamento Coraceros.

Se identificó una correlación entre el área de las zonas y los buffer de las entidades arqueológicas de tal manera que mientras mayor es el tamaño de las primeras, menor es la densidad arqueológica (relación entre superficie de la zona y superficie de las áreas buffer de entidades arqueológicas) de las segundas (Tabla 1). Así, la Zona "El Laucho-La Lisera" presenta la mayor densidad (74\%), seguida por la Zona "Centro" (50\%) y Zona "Chinchorro" (41\%), mientras que la Zona "Nueva Esperanza" presenta la menor tasa de densidad (14\%). Este último caso es explicable por el área que corresponde al lecho de los ríos, así como la intervención 


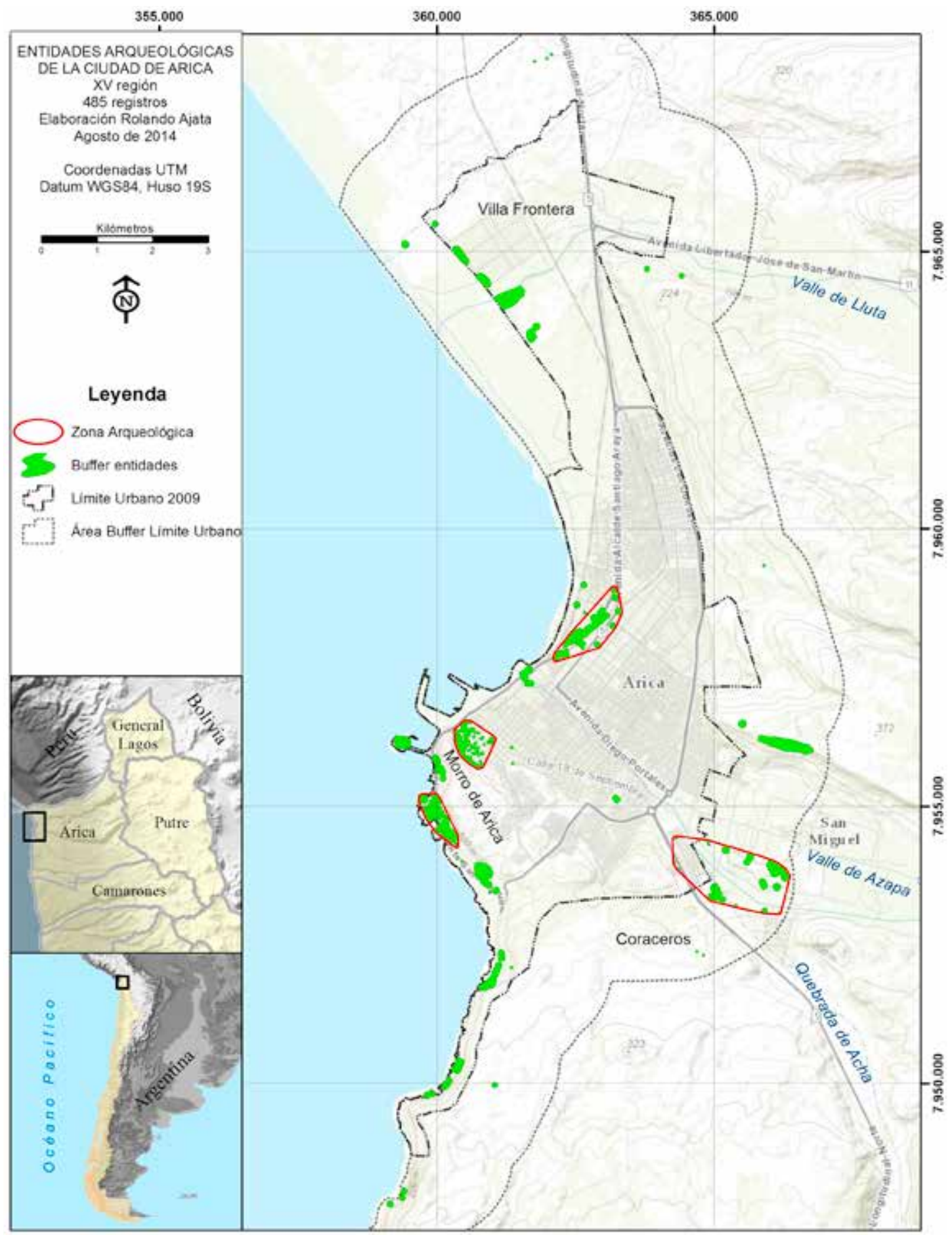

Figura 1. Mapa de distribución de entidades y zonas arqueológicas presentes en área urbana de Arica. 


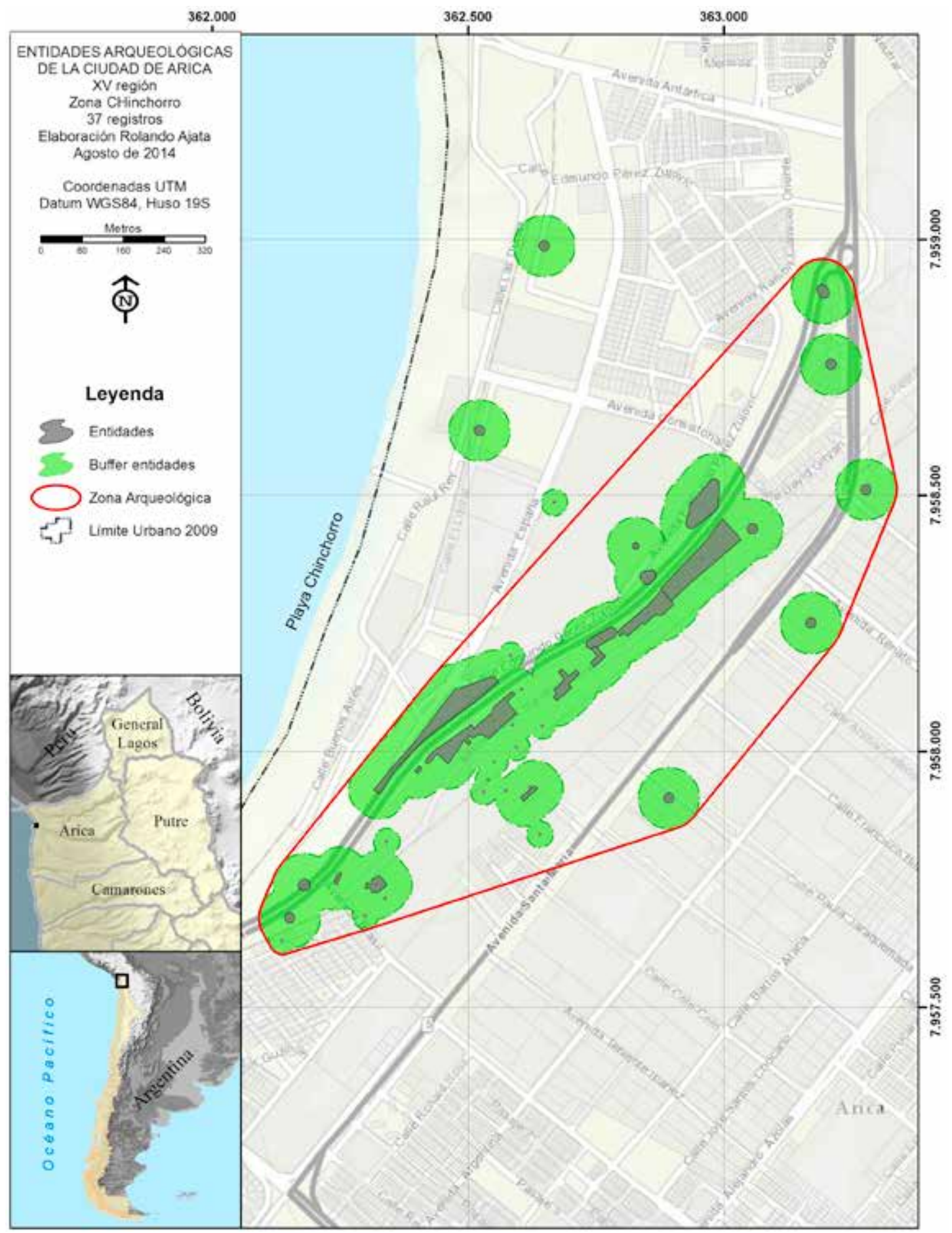

Figura 2. Mapa de Zona Arqueológica "Chinchorro". 


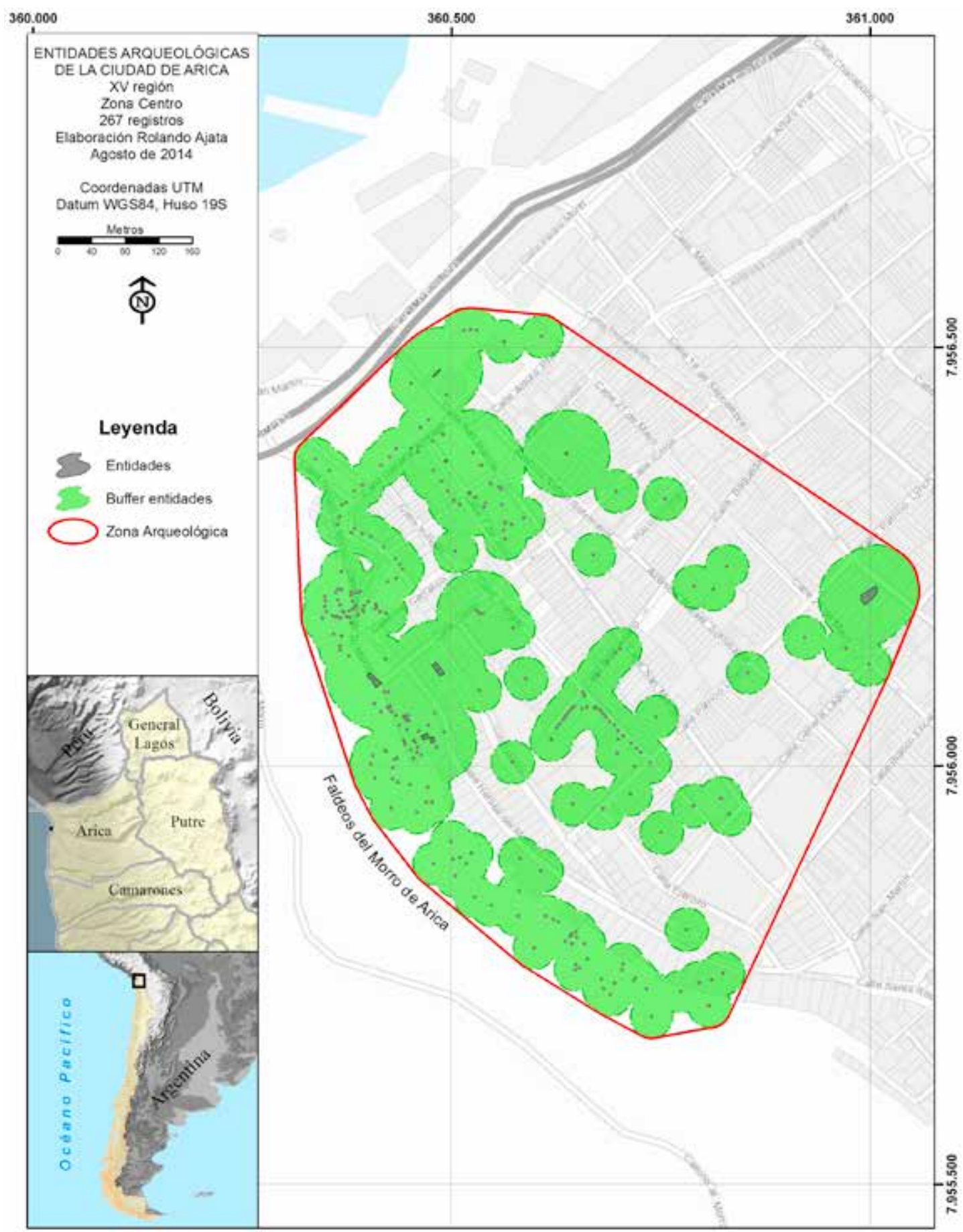

Figura 3. Mapa de Zona Arqueológica "Centro". 


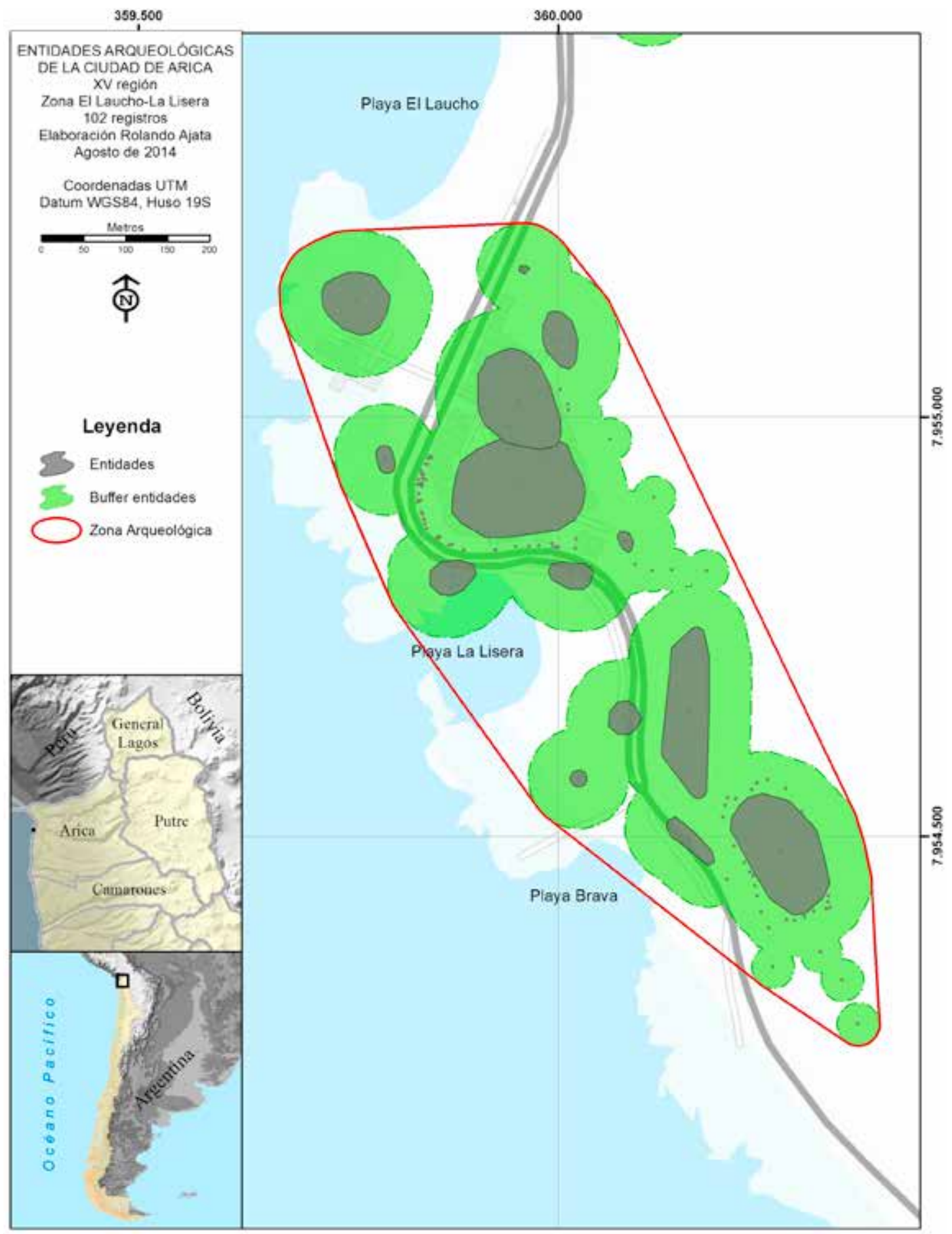

Figura 4. Mapa de Zona Arqueológica "El Laucho-La Lisera”. 


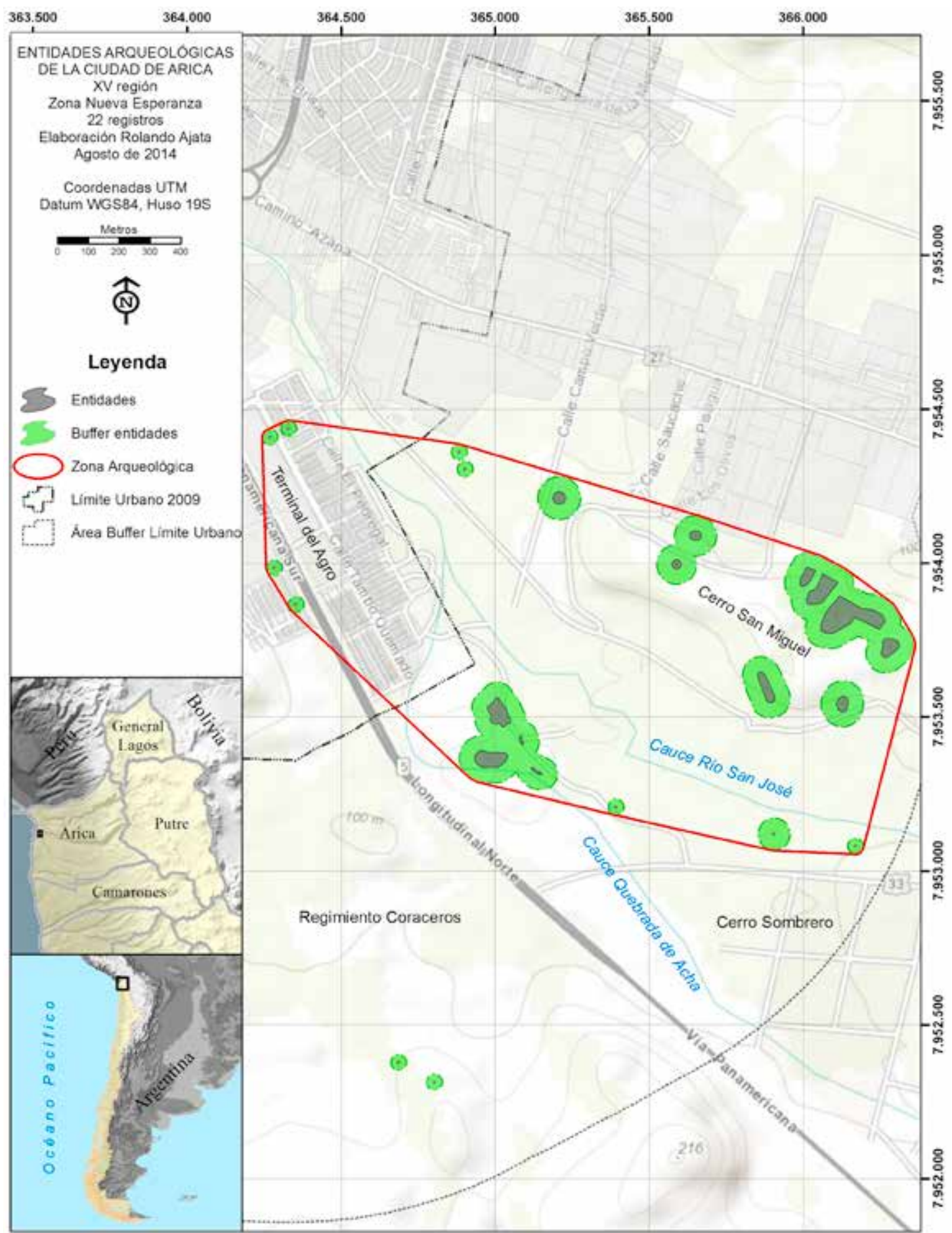

Figura 5. Mapa de Zona Arqueológica "Nueva Esperanza". 
Tabla 1. Caracterización de Zonas Arqueológicas de Arica.

\begin{tabular}{lccccc}
\hline Zona Arqueológica & $\begin{array}{c}\text { Superficie } \\
\left(\mathrm{m}^{2}\right)\end{array}$ & $\mathrm{N}^{\text {o de Entidades }}$ & $\begin{array}{c}\text { Superficie Entidades } \\
\left(\mathrm{m}^{2}\right)\end{array}$ & $\begin{array}{c}\text { Superficie Buffer } \\
\text { de Entidades }\left(\mathrm{m}^{2}\right)\end{array}$ & $\begin{array}{c}\text { Densidad } \\
\text { Arqueológica }\end{array}$ \\
\hline Chinchorro & 708.409 & 37 & 33.632 & 292.228 & 41,3 \\
Centro & 430.768 & 267 & 929 & 215.672 & 50,1 \\
Laucho-Lisera & 340.573 & 102 & 58.674 & 251.126 & 73,7 \\
Nueva Esperanza & 1.931 .455 & 22 & 38.833 & 263.013 & 13,6 \\
\hline
\end{tabular}

de los suelos como áreas de cultivo que debe haber influido fuertemente en la conservación de las áreas arqueológicas.

Por su parte, la Zona "Centro" (Figura 3) es la que presenta la mayor cantidad de entidades arqueológicas a causa de la realización de mayores intervenciones puntuales en el subsuelo, como pozos de sondeo y rescates arqueológicos, así como de la realización de prospecciones superficiales que han dado cuenta de una amplia distribución de elementos arqueológicos en los faldeos del Morro de Arica.

Fuera de estas Zonas se identifican agrupaciones de entidades arqueológicas en los sectores de Villa Frontera e inmediaciones de la desembocadura del río Lluta; desembocadura del río San José; ex-Isla del Alacrán y sección inferior occidental del Morro de Arica; sector Caleta Quiani (pesqueras); sector La Capilla; y borde sur del Cerro Chuño. Otras evidencias arqueológicas se manifiestan de manera más aislada.

\section{Recomendaciones y comentarios finales}

En análisis previos de la relación entre el patrimonio arqueológico con los instrumentos de planificación en Chile, se han propuesto metodologías para su incorporación en los instrumentos de orden provincial o regional (Munita et al. 2010). En este artículo nos hemos enfocado en el ámbito local o comunal, que es el ámbito donde el riesgo de daño a monumentos arqueológicos se hace más frecuente y en el caso particular de Arica, lleva, de hecho, sucediendo por largo tiempo. La dinámica constructiva en el interior de la ciudad y el carácter normativo de los instrumentos de planificación urbana hace más urgente y efectiva la incorporación de este componente arqueológico en los PRC.

Para el caso de Arica, la existencia del Decreto Supremo $N^{\circ} 4867$, ya citado, exige que en el PRC de Arica sean reconocidos y listados los Yacimientos Arqueológicos, en el entendido que son Monumentos Nacionales en la categoría de Monumentos
Arqueológicos y Monumentos Históricos. Al respecto, existe información acumulada por casi 100 años que permite tener un listado con la localización y el tamaño de más de 400 entidades arqueológicas. Para esto, se debe avanzar más allá del trabajo exploratorio de sistematización que se presenta acá, y se deben clasificar las entidades, con el objeto de delimitar adecuadamente y de manera sistemática los conjuntos, yacimientos y zonas arqueológicas.

Ahora bien, una vez establecidos y fijados los Monumentos Nacionales de carácter arqueológico en el PRC, se debe establecer un procedimiento para que la correspondiente DOM identifique las obras que pudieran afectar las entidades y zonas arqueológicas previamente definidas. En dicho caso, la DOM deberá solicitar a los mandantes de las obras, las autorizaciones correspondientes al CMN. En casos necesarios, el CMN podrá requerir procedimientos de Arqueología Preventiva, relacionados con la ejecución de Diagnósticos Arqueológicos, con el objeto de evaluar el subsuelo y fijar, en caso de que sea necesario, las características de los rescates arqueológicos correspondientes.

En el resto de las urbes de Chile, con motivo de las modificaciones a los PRC se debe hacer el esfuerzo por sistematizar los hallazgos arqueológicos conocidos en el interior de las ciudades, incluso en aquellas que posean una densa historia constructiva, de tal manera que permita documentar las trazas urbanas históricas de tiempos coloniales y republicanos. En este sentido, se deberían delimitar los Cascos Antiguos como Zonas Especiales, donde se deberán solicitar Diagnósticos Arqueológicos, tal cual hoy en día sucede en el centro de Santiago ${ }^{15}$. Además, se debe entender que el suceso de hallazgos de evidencias arqueológicas es un proceso dinámico y permanente, por lo que se requerirá de una estrecha coordinación entre el MINVU, la DOM y el CMN.

En este artículo hemos visto la necesidad de hacer una gestión más efectiva del Patrimonio Arqueológico de las ciudades. Para esto se requiere adecuar nuestra actual legislación a las recomendaciones 
internacionales y teniendo en consideración las experiencias favorables al respecto. Se deberán hacer los esfuerzos para incorporar en la Ley General de Urbanismo y Construcción una nueva categoría de protección del Patrimonio Cultural, denominada Zona de Resguardo Arqueológico o Zona de Servidumbre Arqueológica (Querol 2010), que tendrán procedimientos particulares para minimizar el riesgo de afectación a Monumentos Arqueológicos del subsuelo. La definición de estas zonas estará dada por la realización de estudios específicos denominados generalmente como Cartas Arqueológicas, donde mediante la recopilación de datos y su análisis territorial nos permitiría identificar las áreas con probabilidades ciertas de contar con depósitos arqueológicos.
Finalmente, observadores desde otros ámbitos de desarrollo de las ciudades nos podrán indicar que estos esfuerzos de protección arqueológica no son acordes con nuestro actual nivel de desarrollo económico y social del país. Sin embargo, este esfuerzo es válido desde el momento en que nuestra propia legislación vigente protege todos los recursos arqueológicos, teniendo como base el valor científico intrínseco que este posee. Si establecemos acciones efectivas de gestión y uso de los recursos arqueológicos, estos bienes tendrán valores adicionales al valor científico, relativos al valor educativo, identitario y económico. Esfuerzos legales y de procedimientos técnicos en ese sentido harán que los bienes arqueológicos en el subsuelo de las ciudades dejen de percibirse como problemas y sean entendidos como oportunidades sociales.

\section{Referencias Citadas}

Ajata, R.

2006 Certificado de reconocimiento arqueológico, cerro San Miguel sector Nueva Aurora-Lombardi, KM 3, 5 del valle de Azapa. Comisión Asesora de Monumentos Nacionales, Región de Arica y Parinacota. Manuscrito en posesión del autor.

Ajata, R.

2011 Estudio de línea base arqueológica del borde costero de la Comuna de Arica (Ambar S.A.). Dirección Regional de Obras Portuarias, Ministerio de Obras Públicas, Arica. Manuscrito en posesión del autor.

Allison, M., G. Focacci, B. Arriaza, V. Standen, M. Rivera y J. Lowenstein

1984 Chinchorro. Momias de preparación complicada. Métodos de Momificación. Chungara 13: 155-185.

Álvarez, L.

1969 Un cementerio prehispánico con momias de preparación complicada. Rehue 2: 181-190.

Álvarez, L. (Ed.)

1996 Reedición de Boletines del Museo Regional de Arica. Universidad de Tarapacá.

Arriaza, B., V. Standen, E. Belmonte, E. Rosello y F. Nials.

2001 The peopling of the Arica Coast during the preceramic: A preliminary view. Chungara 33(2): 31-16.

Barreiro, D.

2012 Arqueología aplicada y patrimonio: memoria y utopía. Complutum 23(2): 33-50.

Bird, J.

1988 [1943] Excavaciones en el Norte de Chile. Traducción de M. Rivera. Ediciones Universidad de Tarapacá, Arica.

Blake, J. H.

1878 Notes on a Collection from the Ancient Cemetery at the Bay of Chacota, Peru. Eleventh Annual Report of the Trustees of the Peabody Museum of American Archaeology and Ethnology Vol. 2: 277-304, Cambridge.

Bollaert, W.

1860 Antiquarian, Ethnological and Others Researches of New Granada, Equador, Peru and Chile. Trübner\& Co. Paternoster Row, Londres.
Borrero, L. y J. Lanata

1992 Arqueología espacial en Patagonia: Nuestra perspectiva. En Análisis Espacial en la Arqueología Patagónica, L. Borrero y J. Lanata (editores), Ediciones Ayllu, Buenos Aires.

Briones, L. y P. Casanova

2011 Conservación y Restauración de Geoglifos en el Norte de Chile. Consejo Nacional de la Cultura y las Artes, FONDART Regional, Arica.

\section{CNCA/CMN/SNIT}

2010 Situs. Estándares Mínimos de Registro del Patrimonio Arqueológico. Centro Nacional de Conservación y Restauración y DIBAM-CMN, Santiago.

Carrasco, C.

2006 La práctica arqueológica y la actual construcción de conocimiento arqueológico en Chile. Boletín de la Sociedad Chilena de Arqueología 39: 35-49.

Chacama, J., L. Briones e I. Muñoz

1989-1990 Puesta en valor de un sitio monumental prehispánico. Tambo Zapahuira 1 (Az 40). Hombre y Desierto 3-4: 23-37.

D'Orbigny, A.

2002 [1826-1833] Viaje a la América Meridional, Tomo III. Instituto Francés de Estudios Andinos y Plural Editores, La Paz.

Dauelsberg, P.

1985 Faldas del Morro. Fase cultural agroalfarera temprana. Chungara 14: 7-44.

Dauelsberg, P.

1989-1990 Algunas consideraciones en torno a la restauración y reconstrucciones de bienes inmuebles prehispánicos en la zona de Arica. Hombre y Desierto 3-4: 19-22.

Dauelsberg, P., L. Briones, S. Chacón, E. Vásquez y L. Álvarez 1975 Los grandes geoglifos del valle del Lluta. Revista Universidad de Chile Sede Arica 3: 13-16.

Ewbank, T.

1855 A description of the Indian antiquities brought from Chile and Peru. U.S. Naval Astronomical Expedition to 
the Southern Hemisphere, During Years 1849, 50, 51, 52, Vol. 2: 111-150.

Fernández, S.

2008 Patrimonio Arqueológico y Planificación Territorial. Estrategias de Gestión para Andalucía. Junta de Andalucía y Universidad de Sevilla, Sevilla.

Focacci, G.

1974 Excavaciones en el cementerio Playa Miller 7, Arica (Chile). Chungara 3: 23-74.

Focacci, G. y S. Chacón

1989 Excavaciones arqueológicas en los Faldeos del Morro de Arica. Sitios Morro 1/6 y 2/2. Chungara 22: 15-62

Frezier, A.

1982 [1716] Relación del Viaje por el Mar del Sur. Traducción de M. Guerin. Fundación Biblioteca Ayacucho, Caracas.

Galdames, L. y R. Ruz

2010 La Junta de Adelanto de Arica y John V. Murra. Dos lecturas sobre el desarrollo andino en el Norte de Chile. Chungara, Revista de Antropología Chilena 42(1): 257-270.

Galeno-Ibaceta, C.

2013 Arica, la Junta de Adelanto y las convergencias del brutalismo. Manuscrito inédito presentado en el X Seminario DOCOMOMO Brasil, Curitiba.

Gänger, S.

2009 Conquering the Past: Post-War Archaeology and Nationalism in the Borderlands of Chile and Peru, c. 18801920. ComparativeStudies in Society and History 51(4): 691-714.

González, P.

2004 Protección jurídica del Patrimonio Cultural: Logros y encrucijadas del patrimonio antropoarqueológico chileno. Chungara Revista de Antropología Chilena 36 (Volumen Especial 1): 509-522.

Guillén, J.

2006 Las Cartas Arqueológicas: Documentar para gestionar. Boletín de Patrimonio Histórico 3-4: 28-31.

Jofré, D. y R. Ajata

2009 Informe de sondeos arqueológicos. Proyecto tienda comercial y supermercado Arica, 21 de Mayo 501, Comuna de Arica, Región de Arica y Parinacota. Comisión Asesora de Monumentos Nacionales, Región de Arica y Parinacota. Manuscrito en posesión de los autores.

Lara, R.

1972-1973 Un año más del Museo Arqueológico San Miguel de Azapa. Chungara 1-2: 7-9

Lémuz, C. y K. Aranda

2008 Mapa de Áreas Arqueológicas Potenciales del Valle de La Paz. Gobierno Municipal de La Paz y Oficialía Mayor de Culturas, La Paz.

Llavori de Micheo, R.

1998 Arqueología y planificación territorial. Un procedimiento aplicado a la arqueología medioambiental. Complutum 9 : 311-334.

MINVU

2010 Circular $N^{\circ} 768$ (DDU 240). División de Desarrollo Urbano, MINVU, Santiago.

Mostny, G.

1944 Excavaciones en Arica. Boletín del Museo Nacional de Historia Natural 22: 135-145.

Munita, D., F. Peña-Cortés y A. Farías

2013 Arqueología y planificación territorial en Chile, situación actual y perspectivas. El caso de estudio de la Provincia de Cautín, Región de Araucanía. Chungara Revista de Antropología Chilena 45(2): 293-310.

Muñoz, I. y J. Chacama

1982 Investigaciones arqueológicas en las poblaciones precerámicas de la costa de Arica. Documentos de Trabajo 2. Universidad de Tarapacá, Arica.

Muñoz, I., B. Arriaza y A. Aufderheide (editores)

1993 Acha 2 y los Orígenes del Poblamiento Humano en Arica. pp. 21-46, Ediciones Universidad de Tarapacá, Arica. Ortúzar, S.

2010 Introducción a la Planificación Territorial. Ediciones Universidad Central, Santiago.

Portilla, M.

2013 Plan de Mitigación Arqueológica, Proyecto "Remediación de Suelos para la Reparación y rehabilitación de la Vía Férrea Arica y Visviri” (RCA 018/2008) Ferrocarril Arica La Paz". Empresa de Ferrocarril Arica-La Paz. Consejo de Monumentos Nacionales. Manuscrito en posesión del autor.

Portilla, M. y R. Ajata

2010a Excavaciones arqueológicas en la Ex Aduana de Arica. Dirección de Arquitectura del Ministerio de Obras Públicas, Región de Arica y Parinacota. Manuscrito en posesión de los autores.

Portilla, M. y R. Ajata

2010b Excavaciones arqueológicas en la Catedral San Marcos de Arica. Dirección de Arquitectura del Ministerio de Obras Públicas, Región de Arica y Parinacota. Manuscrito en posesión de los autores.

Querol, M. A.

2010 Manual de Gestión del Patrimonio Cultural. Ediciones Akal, Madrid.

Sánchez, R.

2001 Ordenamiento Territorial. Instituto Interamericano para la Agricultura (IICA), Santiago.

Santoro, C. y G. Espinosa

2000 SarañPuriña: Entre la Puna y el Mar: Azapa 10.000 años de Movilidad Andina. Taller de Estudios Andinos, Arica.

Schaedel, R. (editor)

1957 Arqueología Chilena. Contribuciones al Estudio de la Región Comprendida entre Arica y La Serena. Centro de Estudios Antropológicos, Universidad de Chile, Santiago.

Standen, V.

2003 Bienes funerarios del cementerio Chinchorro Morro 1: Descripción, análisis e interpretación. Chungara, Revista de Antropología Chilena 35(2): 175-207.

SUBDERE

2011 Plan Regional de Ordenamiento Territorial: Contenido y Procedimiento. Departamento de Políticas y Descentralización, División de Políticas y Estudios, Santiago.

Temiño, I.

2010 Teoría y práctica de los hallazgos arqueológicos. Patrimonio Cultural y Derecho 14: 171-189.

Universidad de Tarapacá

2012 Estudio Básico de Diagnóstico y Plan de Manejo Reservas Arqueológicas Chinchorro, Arica. Departamento de Antropología. Gobierno Regional de Arica y Parinacota, Arica.

Uhle, $M$.

1919 La arqueología de Arica y Tacna. Boletín de la Sociedad de Estudios Históricos Americanos 3(7-8): 1-48. 


\section{Notas}

1 La Junta de Adelanto de Arica fue una institución públicoprivada que funcionó entre 1958 y 1976. Significó una experiencia exitosa de descentralización, al que se le dispusieron fondos estatales con una autonomía regional de decisiones que impulsó el desarrollo económico y social del antiguo Departamento de Arica mediante una cartera de inversiones y estudios (Galdames y Ruz 2010; GalenoIbaceta 2013)

2 Esta documentación se ubica en el Volumen 79: Actas del Consejo 1970 Enero-Diciembre del Fondo Estudios Técnicos de la Junta de Adelanto de Arica, Archivo Histórico Vicente Dagnino de la Universidad de Tarapacá. Se revisaron el "Acta No 654 del 14 de enero de 1970 de la Comisión Turismo, Urbanismo y Obras Públicas", pp. 1-5 (en adelante JAA a) y el "Acuerdo 4.400 del acta 31/69 Programa de la Corporación de Mejoramiento Urbano para el año 1970. Loteo La Lisera", pp. 21-25 (en adelante JAA b). Documentación localizada por el director del AHVD, académico Rodrigo Ruz Zagal y socializada entre el circuito de arqueólogos locales.

3 Entre los naturalistas y exploradores científicos que describen restos arqueológicos y eventualmente los recolectan y trasladan a Europa y Norteamérica, destacan A. Frezier (1982 [1716]), A. D’Orbigny (2002 [1826-1833]), J. Blake (1878), T. Ewbank (1855) y W. Bollaert (1860).

4 El Museo Regional de Arica es antecedente directo del universitario Museo Arqueológico San Miguel de Azapa, primero dependiente de la Universidad del Norte (19671982) y luego de la Universidad de Tarapacá.

5 Sin embargo, destacan los esfuerzos recientes en el sector de Faldeos El Morro, relativos a la postulación de las momias Chinchorro como Patrimonio de la Humanidad (UTA 2012) y la puesta en valor del Museo de Sitio "Colon 10" de la Universidad de Tarapacá.

6 El CMN es un organismo técnico y colegiado del Estado, dependiente del Ministerio de Educación. Si bien fue creado en 1925, recién el año 1970 se ordena su funcionamiento y su ámbito de acción mediante la Ley $N^{\circ} 17.288$ de Monumentos Nacionales. Sin embargo, no será hasta la década de 1990 que su gestión se hace efectiva con la instauración de una Secretaría Ejecutiva y planta de profesionales. Si bien es un organismo centralizado, cuyas decisiones se toman en Santiago, ha ido conformando oficinas asesoras regionales para lograr aproximaciones locales a temas que luego se sancionan desde el nivel central.

7 La virtual creación del Ministerio de Cultura y Patrimonio, que incluiría administrativamente las tres principales instituciones que trabajan con el componente patrimonial, como el Consejo de la Cultura y las Artes, la Dirección de Bibliotecas, Archivos y Museos y el CMN, hasta el momento no parece asegurar un ordenamiento conceptual al respecto.

8 "Artículo $22^{\circ}$. Por el solo ministerio de la ley, son Monumentos Arqueológicos de propiedad del Estado los lugares, ruinas, yacimientos y piezas antropo-arqueológicas que existan sobre o bajo la superficie del territorio nacional". Dicha protección preexistente al conocimiento y registro de las evidencias se sustenta en el valor científico de las evidencias en relación con su contexto original y en su extrema fragilidad. Pero también se trata de una definición bastante tautológica y que en la práctica requiere de la participación exclusiva de un arqueólogo (y de ningún otro profesional).

9 La Ley $N^{\circ} 17.288$ establece cinco categorías para los Monumentos Nacionales, a saber, Monumentos Históricos, Zonas Típicas, Santuarios de la Naturaleza, Monumentos Arqueológicos (y paleontológicos) y Monumentos Públicos. A diferencia de los Monumentos Arqueológicos que son protegidos "por el solo ministerio de la ley", los Monumentos Históricos (junto con las Zonas Típicas y Santuarios de la Naturaleza) requieren de un decreto específico que los declare. Esta declaración implica un estudio que incluye su caracterización, los valores patrimoniales que posee, y sus límites efectivos.

10 Incluso hoy, pese a que no existe un procedimiento específico para intervenciones arqueológicas en el marco del impacto ambiental, ya que nuestra legislación está pensada para excavaciones de objetivos académicos, se toman este tipo de decisiones en el interior del CMN acerca de qué se conserva o incluso qué porcentaje de yacimientos se excavan y rescatan para dar paso a la ejecución de proyectos de inversión.

11 Entre estos instrumentos sectoriales tenemos el Sistema de Evaluación de Impacto Ambiental (administrado por el Ministerio de Medio Ambiente), el Sistema Nacional de Áreas Silvestres Protegidas del Estado (administrado por CONAF), los Distritos de Conservación (administrados por el Ministerio de Agricultura), y las Zonas de Interés Turístico (definidos por SERNATUR). Se extraña que organismos con importante representación en el territorio, como el Ministerio de Medio Ambiente o el Ministerio de Bienes Nacionales no tengan un rol más preponderante en la Planificación Territorial.

12 En sentido estricto las Zonas de Conservación Histórica deberían ser denominadas como Zonas de Conservación Urbanística, ya que el término "histórico" es muy amplio, pudiendo servir incluso para incluir zonas arqueológicas.

13 Durante la realización de este artículo se estaba ejecutando el estudio "Modificación del Plan Regulador Comunal de Arica", a cargo de la Consultora Polis y cuyo mandante es el MINVU en convenio con el Gobierno Regional y la Municipalidad de Arica.

14 Se podría asimilar a lo que se ha denominado 'Hallazgo Aislado' en la nomenclatura SITUS (CNCA/CMN/SNIT 2009).

15 Actualmente, como parte de la Modificación del PRC de Santiago relativa al Centro Histórico (2008) se estableció que en el interior de las Zonas Típicas las intervenciones en el subsuelo de predios que no han sido modificados en los últimos 50 años requerirán de la realización de Evaluaciones Arqueológicas, con la finalidad de descartar la presencia de Monumentos Arqueológicos. 